ISSN 0103-9954

\title{
FITOSSOCIOLOGIA E DIVERSIDADE FLORÍSTICA EM ÁREA DE CERRADO SOB VÁRIOS NÍVEIS DE ANTROPIZAÇÃO, RIO PARDO DE MINAS, MG ${ }^{1}$
}

\author{
PHYTOSOCIOLOGY AND FLORISTIC DIVERSITY IN A CERRADO AREA UNDER DIFFERENT \\ ANTROPIZATION LEVELS, RIO PARDO DE MINAS, MG
}

\author{
Wanderson Henrique do Couto ${ }^{2}$ Lúcia Helena Cunha dos Anjos ${ }^{3}$ Luciano de Oliveira Toledo ${ }^{4}$ \\ Marcos Gervasio Pereira ${ }^{5}$ Márcio Marques Queiros ${ }^{6}$
}

\section{RESUMO}

Este estudo teve como objetivo avaliar a diversidade e a similaridade florística de ambientes de Cerrado, sob diferentes níveis de antropização por uso agrícola e extrativismo, e gerar base de dados para subsidiar propostas de desenvolvimento sustentável para a região Norte de Minas e sistemas de agricultura tradicional. Foram amostradas 4 áreas nos seguintes ambientes: Areião, Areiãozinho, Chapada de Latossolo e Tabuleiro, cujas identificações foram feitas a partir de informantes-chave na Comunidade Água Boa, em Rio Pardo de Minas (MG). As unidades amostrais foram distribuídas em 8 parcelas de 20 x $50 \mathrm{~m}$, com 5 subparcelas. Foram medidos indivíduos arbóreos com circunferência ao nível do solo maior ou igual a 15 $\mathrm{cm}$. Para análise dos índices fitossociológicos foram calculados os parâmetros densidade, dominância, freqüência, área basal e valor de importância, para cada ambiente. Para a diversidade florística foi calculado o índice de Shannon (H') e para análise da similaridade o índice de Jaccard (Sij). Em todos os ambientes, foi encontrado um total de 477 indivíduos, distribuídos em 21 famílias, com 48 espécies botânicas identificadas e 27 indivíduos não identificados. As cinco famílias mais importantes (maior VI) foram Fabaceae/Papilionoideae, Apocynaceae, Vochysiaceae, Sapotaceae e Fabaceae/Caesalpinoideae. Já as dez espécies de maior importância foram Pouteria ramiflora, Dalbergia miscolobium, Hancornia speciosa, Macherium opacum, Sclerolobium paniculatum var. subvelutinum, Qualea grandiflora, Aspidosperma tomentosum, Byrsonima pachyphylla, Vochysia thyrsoidea e Hymenaea stigonocarpa. O índice H' foi de 3,01; 2,72; 2,48 e 2,09 para Areião, Areiãozinho, Chapada do Latossolo e Tabuleiro, respectivamente. O índice Sij indicou, para todas as combinações entre os ambientes, que existia pouca similaridade florística entre eles.

Palavras-chave: sucessão florestal; inventário florestal; ecossistemas de cerrado; sistemas tradicionais.

\section{ABSTRACT}

The objective of the study was to evaluate diversity and floristic similarity of Cerrado environments, under different levels of anthropization for agricultural usage and extractivism, and to generate a database to subsidize sustainable development proposals for the North region of Minas Gerais State, and traditional agriculture systems. Four areas with different levels of anthropization were sampled, in the following environments: "Areião, Areiãozinho, Chapada de Latossolo and Tabuleiro", whose identifications had been made from key informers in the Água Boa Community, in Rio Pardo de Minas (MG, Brazil). The sampled units were distributed in 8 parcels of $20 \times 50 \mathrm{~m}$, with 5 subplots. The trees with circumference at ground level of $15 \mathrm{~cm}$ or bigger were measured. For analysis of the phytosociology indexes the following parameters were calculated for each environment: density, dominance, frequency, basal area, and importance value. For

1. Parte da Tese de Doutorado do terceiro autor, apresentada ao Curso de Pós-Graduação em Agronomia - Ciência do Solo, Universidade Federal Rural do Rio de Janeiro, BR 465, km 7, CEP: 23890-000, Seropédica (RJ)..

2. Engenheiro Agrônomo, Mestrando em Agronomia - Ciência do Solo, Universidade Federal Rural do Rio de Janeiro, BR 465, km 7, CEP: 23890-000, Seropédica (RJ). whcouto@gmail.com

3. Engenheira Agrônoma, Dr., Professor Associado do Departamento de Solos, Instituto de Agronomia, Universidade Federal Rural Rio de Janeiro, BR 465, km 7, CEP: 23890-000, Seropédica (RJ). Bolsista CNPq e FAPERJ. lanjos@ufrrj.br

4. Engenheiro Florestal, Dr., Professor Instituto Federal de Educação, Ciência e Tecnologia do Espírito Santo, Campus Santa Teresa, Rodovia ES 080, km 21, CEP: 29600-000, São João de Petrópolis (ES). ltoledo@ifes.edu.br

5. Engenheiro Agrônomo, Dr., Professor Associado do Departamento de Solos, Instituto de Agronomia, Universidade Federal Rural Rio de Janeiro, BR 465, km 7, CEP: 23890-000, Seropédica (RJ). Bolsista CNPq e FAPERJ. gervasio@ufrrj.br

6. Acadêmico do Curso de Graduação em Engenharia Florestal, Universidade Federal Rural do Rio de Janeiro, BR 465, km 7, CEP: 23890-000, Seropédica (RJ). mamarks632@yahoo.com.br

Recebido para publicação em 22/11/2007 e aceito em 28/08/2009. 
the floristic diversity the Shannon $\left(\mathrm{H}^{\prime}\right)$ was calculated, and for the analysis of similarity the index of Jaccard index (Sij). In all the environments, it was found a total of 477 individuals, distributed in 21 families, with 48 botanical species identified, and 27 individuals not identified. The five most important (importance value) families was Fabaceae/Papilionoideae, Apocynaceae, Vochysiaceae, Sapotaceae and Fabaceae/Caesalpinoideae. And the ten most important species was Pouteria ramiflora, Dalbergia miscolobium, Hancornia speciosa, Macherium opacum, Sclerolobium paniculatum var. subvelutinum, Qualea grandiflora, Aspidosperma tomentosum, Byrsonima pachyphylla, Vochysia thyrsoidea and Hymenaea stigonocarpa. The H' index was of 3.01; 2.72; 2.48 and 2.09 for "Areião, Areiãozinho, Chapada de Latossolo and Tabuleiro", respectively. The Sij index indicated a small floristic similarity for all the combinations between the environments.

Keywords: forest succession; forest survey; cerrado ecosystems; traditional systems.

\section{INTRODUÇÃO}

O Cerrado é um importante bioma brasileiro e cobre cerca de $25 \%$ do território nacional, constituindo-se por diversas formações vegetais. Sob o ponto de vista físionômico podem ser verificadas as seguintes formações: florestais, mata ciliar, mata de galeria, mata seca e cerradão; savânicas, cerrado sentido restrito, parque de cerrado, palmeiral e veredas; e as formações campestres, campo sujo, campo limpo e campo rupestre (RIBEIRO e WALTER, 2001). Esta diversidade pode ser explicada por se tratar de um bioma de grande extensão territorial, apoiado sobre diversas feições geológicas e, por isso, apresenta grandes variações ambientais, de classes de solo, altitude, latitude e longitude, distribuição de chuvas ao longo do ano, suscetibilidade a incêndios e variações de temperaturas durante todo o ano. Toda essa riqueza encontrase apoiada em uma climatologia e um regime hídrico que colocam o Cerrado na condição de berço de grande parte das águas do continente sul-americano (PIVELLO e COUTINHO, 1996).

Durante o período de 1966-87 o Governo Federal ofereceu incentivos fiscais às empresas vinculadas ou não à produção de florestas, como estímulo ao desenvolvimento econômico deste setor. Neste período grandes áreas de eucalipto foram plantadas no estado de Minas Gerais com a finalidade de suprir a demanda da crescente de carvão-vegetal para a indústria siderúrgica mineira que, até os dias de hoje, constitui-se no maior pólo siderúrgico do país (FERREIRA, 2005). Dentre os principais prejuízos ambientais ocasionados pela substituição da cobertura nativa por povoamento de eucalipto, destacam-se: a diminuição da vazão dos rios, ocasionando intermitência ou mesmo extinção de nascentes em cabeceiras de drenagem; fortes processos erosivos, donde resultou um descontrolado carreamento, por força hídrica, de sedimentos oriundos de áreas preparadas para o plantio, localizadas nas chapadas, para o interior destas drenagens, causando assoreamento e enchimento das várzeas produtivas ou preserváveis (ALHO e MARTINS, 1995). Além disso, o aumento da ocorrência de incêndios como conseqüência das atividades antrópicas causou, em longo prazo, a redução do estrato arbóreo em detrimento do herbáceo (FONSECA e SILVA JÚNIOR, 2004). Esses fatores afetaram a resiliência dos ambientes do Cerrado, definida como o tempo que um atributo leva para retornar ao estado de equilíbrio após ter sido submetido a uma perturbação (PIMM, 1984).

A diminuição de áreas de "gerais" (termo utilizado para denominar áreas de Cerrado de uso comum para extrativismo), onde a vegetação natural, rica em frutos, fonte de madeira, caça e outros produtos importantes para a subsistência, foi substituída pela monocultura, promoveu grande impacto cultural nas populações tradicionais dos "Geraizeiros". Como resultante, a sobrevivência dessas populações tornou-se restrita a áreas marginais para a agricultura.

Esse trabalho teve como objetivo avaliar a diversidade e a similaridade florística de ambientes de Cerrado, sob diferentes níveis de antropização por uso agrícola e extrativismo, e gerar uma base de dados para subsidiar propostas de desenvolvimento sustentável para a região norte de Minas, reduto de comunidades tradicionais de agricultores familiares.

\section{MATERIAL E MÉTODOS}

A área de estudo localiza-se no norte do Estado de Minas Gerais, município de Rio Pardo de Minas, numa faixa de contato entre o cerrado, a caatinga e a mata seca (DAYREL, 1998). A comunidade Água Boa 2, onde se desenvolveu a maior parte deste estudo, é um dos 96 povoamentos do município de Rio Pardo de Minas (IBGE, 2006). É constituída de 81 residências com cerca de 400 moradores. O tamanho médio aproximado das propriedades é de 15 ha, para uma média de 3 ha de área agricultável por propriedade. A 
sub-bacia delimitada pela comunidade (Água Boa 2) possui cotas que vão de 828 a 1.014 metros e uma área de 5.197 ha. Suas coordenadas geográficas (Datum Córrego Alegre) são as seguintes: limite norte -

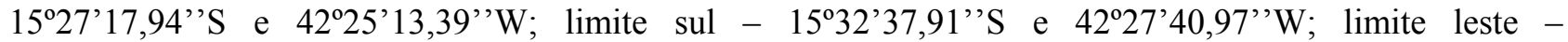
$15^{\circ} 28^{\prime} 21,42^{\prime}$ 'S e $42^{\circ} 24^{\prime} 16,29^{\prime \prime} \mathrm{W}$; limite oeste $-15^{\circ} 29^{\prime} 41,87^{\prime}$ 'S e $42^{\circ} 28^{\prime} 54,18^{\prime}$ 'W.

A pluviosidade media da região é de $783 \mathrm{~mm}$ anuais (série histórica de 1974-2004 da EMATERMG, dados não publicados) concentrados principalmente no verão. O relevo regional é caracterizado por áreas planas nas partes mais altas de paisagem (denominadas chapadas) e nos vales. Como termos locais, as áreas planas com menores cotas e declives são chamadas de 'tabuleiros'. Ocorrem ainda áreas declivosas, entre a chapada e o tabuleiro, chamadas de 'pirambeira'.

A estruturação geológica da região centro-leste do Brasil é, em grande parte, herdada da orogênese brasiliana, que estabeleceu uma rede de faixas de dobramentos separadas por crátons. Destaca-se a feição geotectônica do Cráton do São Francisco e as diversas faixas envolventes. Estas faixas correspondem a bacias sedimentares neoproterozóicas $(1,0$ a $0,54 \mathrm{Ga})$, que experimentaram processos de inversão tectônica durante a orogênese Brasiliana. O Cráton do São Francisco consiste em um embasamento arqueano-paleomesoproterozóico e coberturas sedimentares neoproterozóicas, relacionadas ao Supergrupo São Francisco. Esta unidade apresenta, na base, sequências glacio-marinhas e, para o topo, sedimentos pelito-carbonáticos do Grupo Bambuí. Várias unidades portadoras de diamictitos (que são os tilitos e os arenitos/conglomerados em depósitos flúvio-glaciais) afloram dentro do Cráton do São Francisco (Formações Jequitaí e Bebedouro) e nos cinturões dobrados marginais (UHLEIN et al., 2004).

A glaciação do início do Neoproterozóico foi de caráter regional e ocorreu sobre o Cráton do São Francisco entre 800-750 Ma. Formaram-se as seqüências Jequitaí e Bebedouro, que representam sedimentação glacio-marinha pouco espessa, sobre áreas estáveis do futuro Cráton do São Francisco. Em parte concomitante ao evento glacial, ocorreu abertura de rifts oceânicos e intracontinentais, preenchidos por espessa sedimentação gravitacional (fluxo de detritos e turbiditos), às vezes mostrando ainda influência glacial (clastos caídos ou pingados). Neste contexto, depositou-se o Grupo Macaúbas e sua extensão ao norte (formação bastante característica na região de estudo, em Rio Pardo de Minas-MG), entre outros Grupos. Centros glaciais continentais ou calotas de gelo cobriram a região do futuro cráton e deslocaram-se para bacias marginais marinhas. Fácies glácio-marinhas pouco espessas foram sedimentadas na área estável e foram retrabalhadas por fluxos gravitacionais subaquosos, gradando, lateralmente, para espessos fluxos de detritos (metadiamictitos) e turbiditos (quartzitos, metaritmitos, xistos) em bacias rifte marginais (futuras faixas dobradas) (UHLEIN et al., 2004).

O norte de Minas Gerais é representado em sua maior extensão por formações geológicas de origem metassedimentar. As diversas formações da região, cronologicamente, se situam desde o Pré-cambriano até o Holoceno, destacando-se, por sua maior extensão, aquelas atribuídas ao Pré-cambriano A e ao Cretáceo, além de recobrimentos referidos provavelmente ao Terciário (SEBRAE-MG, 2003).

Rio Pardo de Minas está situado na área de ocorrência de duas formações:

- Pré-cambriano B (3.800 a 2.500 Ma)

- Supergrupo Espinhaço - a litologia é constituída, essencialmente por quartzitos, alguns siltitos, filitos e xistos.

- Pré-cambriano C (1.000 a $570 \mathrm{Ma})$

- Supergrupo São Francisco - Grupo Macaúbas, formado a partir de espessa sedimentação gravitacional de fluxo de detritos e turbiditos oriundos ou não de geleiras glacio-marinhas.

- Recobrimentos (65 a 5,7 Ma)

- Trata-se de materiais arenosos, areno-argilosos, argilo-arenosos e argilosos, referidos provavelmente ao Terciário.

O embasamento geológico da região é predominantemente representado por material de recobrimento do Terciário, com coberturas detríticas arenosas, siltosas, conglomeráticas ou argilosas, por vezes laterizadas e às vezes apresentando banco de seixos mais grosseiros. Litologicamente predominam características de composição arenosa (EMBRAPA/SNLCS, 1979). 
Toda essa complexidade geológica resulta na formação de solos de grande variabilidade na superfície da região de estudo. Entretanto, dentro da sub-bacia Água Boa 2, encontram-se basicamente solos com influência arenítico-quartzítica (áreas mais elevadas de chapadas - acima de $950 \mathrm{~m}$ de altitude correspondendo à localidade do Areião e Chapada Alta, além dos solos formados em condições de sedimentação fluvial - Neossolos e Cambissolos Flúvicos) ou solos de influência argilo-arenosa, arenoargilosa ou argilosa. O primeiro conjunto de solos é resultado da influência clara de mateirais oriundos do Pré-cambriano (B e C - Supergrupo Espinhaço e Supergrupo São Francisco/Grupo Macaúbas) pela grande variabilidade e complexidade dos solos resultantes. O segundo conjunto de solos resulta de sedimentação bem mais recente, predominante nas áreas cultivadas ou manejadas sobre regime de extrativismo pela comunidade, oriunda de recobrimentos depositados no Cenozóico (períodos Terciário e Quaternário - 65 a $0,01 \mathrm{Ma})$.

Para o estudo foram implantadas 8 unidades amostrais, com parcelas de 20 x $50 \mathrm{~m}$ divididas em 5 subparcelas, em quatro ambientes identificados por informantes-chave (pessoas que se destacam na comunidade por conhecerem bem o local, além de possuírem facilidade de expressão) na Comunidade Água Boa 2, na sub-bacia do rio de mesmo nome. Dentre as parcelas, 3 parcelas estavam em Cerrado preservado (Areião) e 2 em área de Cerrado pouco alterado (Areiãozinho), ambas sob Neossolo Quartzarênico. Outras 3 parcelas foram instaladas em área de Cerrado muito alterado pela extração de madeira para produção de carvão, sendo 2 parcelas localizadas em ambiente de chapada, sob Latossolo (Chapada de Latossolo), e 1 em ambiente de 'tabuleiro' (Tabuleiro, sob Cambissolo). Em cada parcela, foram amostrados todos os indivíduos arbóreos com circunferência ao nível do solo (CNS) maior ou igual a 15 centímetros, inclusive os indivíduos mortos que ainda encontravam-se eretos. A referência para medição dos troncos foi definida em função da tortuosidade característica das espécies arbóreas do cerrado que invabilizam a medida à altura do peito. Com base nos dados da CNS e no número de indivíduos, foram calculados os parâmetros fitossociológicos para cada ambiente, tais como: área basal ( $\mathrm{AB})$, densidade relativa (DR), freqüência relativa (FR), dominância relativa (DoR) índices de valor de importância (VI) e de cobertura (VC). Para avaliar a diversidade florística de cada área foi utilizado o Índice de Shannon $\left(\mathrm{H}^{\prime}\right)$ com posterior análise de variância através de teste de Tukey $(0,05)$. A similaridade florística foi avaliada pelo Índice de similaridade de Jaccard (Sij). Os cálculos de parâmetros fitossociológicos foram realizados a partir de metodologia descrita em Sylvestre e Rosa (2002).

Posteriormente foi feito teste de médias (teste de Tuckey a 0,05 ) com os valores encontrados em cada ambiente.

Para verificar a similaridade florística entre as diferentes parcelas ou áreas, utilizou-se o Índice de Jaccard, que expressa a ocorrência de espécies comuns contra as teoricamente possíveis, baseado na presença e ausência das espécies. Este índice varia de 0 (ausência total de similaridade) a 1 (total similaridade).

$\mathrm{Sij}=\mathrm{c} /(\mathrm{a}+\mathrm{b}-\mathrm{c})$

Em que: $\mathrm{a}=$ número de indivíduos da amostra $\mathrm{i} ; \mathrm{b}=$ número de indivíduos da amostra $\mathrm{j} ; \mathrm{c}=$ número de indivíduos que ocorrem tanto em $\mathrm{i}$ como em $\mathrm{j}$.

O material vegetativo e/ou reprodutivo dos indivíduos avaliados foi coletado, identificado com fita adesiva e transportado em saco plástico para o laboratório. Após a coleta o material foi secado e a identificação taxonômica foi realizada através de consultas a bibliografias referentes à vegetação natural das áreas de estudo. Os materiais cuja identificação não foi possível de ser realizada no nível de espécie, a partir de um guia de campo (SILVA JÚNIOR, 2005), foram separados nos níveis de famílias ou gêneros e, posteriormente, comparados com o material existente em herbários da RBR (Universidade Federal Rural do Rio de Janeiro) e JBRJ (Fundação Jardim Botânico do Rio de Janeiro).

\section{RESULTADOS E DISCUSSÃO}

Em todos os ambientes amostrados foi encontrado um total de 477 indivíduos, distribuídos em 21 famílias, com 48 espécies botânicas identificadas (Tabela 1). As famílias com maior número de espécies foram Myrtaceae e Fabaceae/Mimosoideae (5), Apocynaceae, Malpighiaceae, Fabaceae/Papilionoideae e Vochysiaceae, (4), Sapotaceae (3). No entanto, as famílias que apresentaram maior número de indivíduos foram Fabaceae/Papilionoideae com 65 indivíduos (13,6\%), seguidas por Apocynaceae com 52 indivíduos $(10,9 \%)$, Sapotaceae e Caesalpinoideae com 50 indivíduos cada uma (10,5\%), Vochysiaceae $45(9,43 \%)$ e 
Malpighiaceae com 41 (8,59\%).

Oliveira (2006), avaliando níveis de intervenção na florística e diversidade arbórea em área de Cerrado stricto sensu em Brasilândia - MG, também encontrou a família Fabaceae/Papilionoideae apresentando o maior número de indivíduos, o que indica a grande capacidade de adaptação das espécies dessa família nas condições edafoclimáticas características do bioma Cerrado.

As espécies com maior ocorrência foram Pouteria ramiflora com 47 indivíduos $(9,85 \%)$, Machaerium opacum com 39 (8,18\%), Qualea grandiflora com 29 (6,08\%), Sclerolobium paniculatum var. subvelutinum 28 (5,87\%), e Hancornia speciosa e Byrsonima pachyphylla com 26 indivíduos cada (5,45\%). Assunção e Felfili (2004), Felfili et al. (1994) e Meira Neto e Saporetti Junior (2002) confirmam a ocorrência comum das espécies citadas em áreas de Cerrado stricto sensu e Cerrado rupestre.

TABELA 1: Famílias e espécies com nomes locais amostrados na comunidade de Água Boa 2, Rio Pardo de Minas (MG).

TABLE 1: Families and species with local names, Água Boa 2 community, Rio Pardo de Minas (MG).

\begin{tabular}{|c|c|c|}
\hline Família & Nome Científico & Nome Local \\
\hline \multirow{2}{*}{ Annonaceae } & Annona coriacea Mart. & Marolo-do-cerrado \\
\hline & Annona crassiflora Mart. & Araticum-do-cerrado \\
\hline \multirow{4}{*}{ Apocynaceae } & Aspidosperma tomentosum Mart. & Peroba-do-serrado \\
\hline & Hancornia speciosa B. A. Gomez & Mangaba \\
\hline & Himatanthus obovatus (Müll. Arg.) Woodson & Pau-de-leite \\
\hline & Hymatanthus sp. & \\
\hline Araliaceae & $\begin{array}{l}\text { Schefflera macrocarpa (Cham. \& } \\
\text { Schltdl.) Frodin }\end{array}$ & Mandiocão-do-cerrado \\
\hline \multirow{2}{*}{ Asteraceae } & Eremanthus glomeraptus Less. & Candeia \\
\hline & Eremanthus sp. & Candeinha \\
\hline Asteraceae & Lychnophora sp. & Canela-de-ema \\
\hline \multirow{2}{*}{ Bignoniaceae } & Tabebuia ochracea (Cham.) Standl. & Ipê-amarelo-do-cerrado \\
\hline & Tabebuia sp. & Ipê \\
\hline Caryocaraceae & Caryocar brasiliense Cambess. & Pequi \\
\hline Combretaceae & Terminalia fagifolia Mart. & Mussambé \\
\hline Ebehnaceae & Diospyros burchellii Hiern & Olho-de-boi \\
\hline \multirow{2}{*}{ Erythroxylaceae } & Erythroxylum sp.1 & Mercurio \\
\hline & Erythroxylum sp.2 & Mercurio \\
\hline Euphorbiaceae & Euphorbiaceae sp. & Bajantá \\
\hline Salicaceae & Casearia sylvestris $\mathrm{Sw}$. & Lingua-de-tamanduá \\
\hline \multirow{2}{*}{ Clusiaceae } & Kielmeyera coriacea Mart. \& Zucc. & Pau-santo \\
\hline & Kielmeyera speciosa A. St.-Hil. & Pau-santo \\
\hline \multirow[b]{2}{*}{ Fabaceae/Caesalpinoideae } & Hymenaea stigonocarpa Mart. ex Hayne & Jatobá-do-cerrado \\
\hline & $\begin{array}{l}\text { Sclerolobium paniculatum } \\
\text { var. subvelutinum Benth. }\end{array}$ & Veludo \\
\hline \multirow{5}{*}{ Fabaceae/Mimosoideae } & $\begin{array}{l}\text { Enterolobium gummiferum (Mart.) } \\
\text { J. F. Macbr. }\end{array}$ & Tamboril \\
\hline & Mimosa sp. & Mimosa \\
\hline & Piptadenia viridiflora (Kunth) Benth. & Espinheiro \\
\hline & Plathymenia reticulata Benth. & Vinhático-do-campo \\
\hline & Stryphnodendron adstringens (Mart.) Coville & Barbatimão \\
\hline \multirow{4}{*}{ Fabaceae/Papilionoideae } & Ascosmium dasycarpum (Vog.) Yakovlev & Unha-d'anta \\
\hline & Bowdichia virgilioides Kunth & Sucupira-preta \\
\hline & Dalbergia miscolobium Benth. & Caviúna-do-cerrado \\
\hline & Machaerium opacum Vogel & Jacarandá-cascudo \\
\hline
\end{tabular}


TABELA 1: Continuação ...

TABLE 1: Continued...

\begin{tabular}{|c|c|c|}
\hline Família & Nome Científico & Nome Local \\
\hline Loganiaceae & Strychnos pseudoquina A. St.-Hil. & Quina-do-cerrado \\
\hline \multirow{4}{*}{ Malpighiaceae } & Byrsonima pachyphylla A. Juss. & Murici \\
\hline & Byrsonima verbascifolia (L.) Rich ex Juss. & Muricizão \\
\hline & Heteropterys byrsonimifolia A.Juss. & Murici-macho \\
\hline & Heteropterys sp. & Marra-vaqueiro \\
\hline Melastomataceae & Miconia ferruginata DC. & Pixirica \\
\hline \multirow{7}{*}{ Myrtaceae } & Eucalyptus sp. & Eucalipto (brotação) \\
\hline & Eugenia dysenterica DC. & Cagaita \\
\hline & Eugenia punicifolia (Kunth) DC. & Murta \\
\hline & Eugenia strictopetala DC. & Araçá \\
\hline & Myrtaceae & Myrtaceae \\
\hline & Psidium pohlianum $\mathrm{O}$. Berg. & Araçá \\
\hline & Psidium sp. & Myrtaceae \\
\hline \multirow{3}{*}{ Sapotaceae } & Pouteria ramiflora (Mart.) Radlk. & Morcegueira \\
\hline & Pouteria sp. & Morcegueira \\
\hline & Pouteria torta (Mart.) Radlk. & Cabeluda \\
\hline \multirow{4}{*}{ Vochysiaceae } & Qualea grandiflora Mart. & Pau-terra-grande \\
\hline & Qualea multiflora Mart. & Pau-terra-liso \\
\hline & Qualea parviflora Mart. & Pau-terra-roxo \\
\hline & Vochysia thyrsoidea Pohl & Pau-d'água \\
\hline
\end{tabular}

No ambiente identificado como Areião foram amostrados 195 indivíduos, pertencentes a 16 famílias e 35 espécies (Tabela 2). As espécies com maior valor de importância foram Machaerium opacum $(33,41)$, Caryocar brasiliense $(21,94)$, Qualea grandiflora $(21,85)$ e Pouteria ramiflora $(21,57)$. A área basal foi de $4,4713 \mathrm{~m}^{2} \cdot \mathrm{ha}^{-1}$ e o valor de Shannon (H') foi de 3,01.

Analisando a Tabela 2, os parâmetros que mais contribuíram para a determinação da importância das espécies foram a densidade relativa (DR) e a dominância relativa (DoR), fato que pode ser visualizado pela maior ocorrência e tamanho dos indivíduos mais importantes em cada ambiente. Apesar de Machaerium opacum apresentar VI maior do que Caryocar brasiliense esta última obteve maior área basal, indicando que, não fosse o número maior de indivíduos da primeira esta espécie seria a mais importante deste ambiente. De fato, segundo informações locais, é comum encontrar indivíduos de grande por de $C$. brasiliense naquela região, sendo seus frutos muito apreciados pela comunidade local.

As espécies Qualea grandiflora, Pouteria ramiflora, Hancornia speciosa e Dalbergia miscolobium e Caryocar brasiliense destacaram-se nos ambientes estudados, aparecendo sempre entre as espécies com maior valor de importância. Amaral (2006) observou o mesmo comportamento no levantamento em Brasília com as espécies Sclerolobium paniculatum var. subvelutinum, Qualea grandiflora e Byrsonima pachyphylla, onde a variável com maior peso nos índices de valor de importância foi o porte das plantas. 
TABELA 2: Parâmetros estruturais e fitossociológicos no ambiente do Areião (Neossolo Quartzarênico) na comunidade Água Boa 2, Rio Pardo de Minas (MG).

TABLE 2: Structural and phytosociology parameters in the Areião (Neossolo Quartzarênico) environment, Água Boa 2 community, Rio Pardo de Minas (MG).

\begin{tabular}{|c|c|c|c|c|c|c|c|}
\hline Nome Científico & $\begin{array}{c}\mathrm{AB} \\
\left(\mathrm{m}^{2} \mathrm{ha}^{-1}\right)\end{array}$ & IND & DR & FR & DoR & VI & $\mathrm{VC}$ \\
\hline Machaerium opacum & 0,5287 & 32 & 16,41 & 5,17 & 11,82 & 33,41 & 28,24 \\
\hline Caryocar brasiliense & 0,6665 & 7 & 3,59 & 3,45 & 14,91 & 21,94 & 18,50 \\
\hline Qualea grandiflora & 0,4020 & 15 & 7,69 & 5,17 & 8,99 & 21,85 & 16,68 \\
\hline Pouteria ramiflora & 0,4808 & 11 & 5,64 & 5,17 & 10,75 & 21,57 & 16,39 \\
\hline N. I. & 0,3363 & 22 & 11,28 & 1,72 & 7,52 & 20,53 & 18,80 \\
\hline Hymenaea stigonocarpa & 0,3652 & 10 & 5,13 & 5,17 & 8,17 & 18,47 & 13,30 \\
\hline Byrsonima pachyphylla & 0,1810 & 15 & 7,69 & 5,17 & 4,05 & 16,91 & 11,74 \\
\hline Kielmeyera coriacea & 0,1653 & 13 & 6,67 & 5,17 & 3,70 & 15,54 & 10,36 \\
\hline Eugenia dysenterica & 0,1827 & 8 & 4,10 & 3,45 & 4,09 & 11,64 & 8,19 \\
\hline Hancornia speciosa & 0,1104 & 6 & 3,08 & 5,17 & 2,47 & 10,72 & 5,55 \\
\hline Schefflera macrocarpa & 0,1071 & 6 & 3,08 & 3,45 & 2,40 & 8,92 & 5,47 \\
\hline Qualea parviflora & 0,0451 & 5 & 2,56 & 5,17 & 1,01 & 8,75 & 3,57 \\
\hline Mortas & 0,2267 & 6 & 3,08 & 0,00 & 5,07 & 8,15 & 8,15 \\
\hline Strychnos pseudoquina & 0,0835 & 4 & 2,05 & 3,45 & 1,87 & 7,37 & 3,92 \\
\hline Tabebuia ochracea & 0,1064 & 2 & 1,03 & 3,45 & 2,38 & 6,85 & 3,40 \\
\hline Aspidosperma tomentosum & 0,0765 & 3 & 1,54 & 3,45 & 1,71 & 6,70 & 3,25 \\
\hline Byrsonima verbascifolia & 0,0327 & 4 & 2,05 & 3,45 & 0,73 & 6,23 & 2,78 \\
\hline Psidium pohlianum & 0,0296 & 3 & 1,54 & 3,45 & 0,66 & 5,65 & 2,20 \\
\hline Qualea multiflora & 0,1152 & 2 & 1,03 & 1,72 & 2,58 & 5,33 & 3,60 \\
\hline Annona coriacea & 0,0054 & 3 & 1,54 & 3,45 & 0,12 & 5,11 & 1,66 \\
\hline Sclerolobium paniculatum var. subvelutinum & 0,0894 & 1 & 0,51 & 1,72 & 2,00 & 4,24 & 2,51 \\
\hline Hymatanthus sp. & 0,0129 & 2 & 1,03 & 1,72 & 0,29 & 3,04 & 1,31 \\
\hline Dalbergia miscolobium & 0,0286 & 1 & 0,51 & 1,72 & 0,64 & 2,88 & 1,15 \\
\hline Eugenia strictopetala & 0,0055 & 2 & 1,03 & 1,72 & 0,12 & 2,87 & 1,15 \\
\hline Erythroxylum sp.1 & 0,0049 & 2 & 1,03 & 1,72 & 0,11 & 2,86 & 1,14 \\
\hline Enterolobium gummiferum & 0,0191 & 1 & 0,51 & 1,72 & 0,43 & 2,66 & 0,94 \\
\hline Heteropterys sp. & 0,0154 & 1 & 0,51 & 1,72 & 0,34 & 2,58 & 0,86 \\
\hline Bowdichia virgilioides & 0,0103 & 1 & 0,51 & 1,72 & 0,23 & 2,47 & 0,74 \\
\hline Pouteria sp. & 0,0097 & 1 & 0,51 & 1,72 & 0,22 & 2,45 & 0,73 \\
\hline Pouteria torta & 0,0092 & 1 & 0,51 & 1,72 & 0,21 & 2,44 & 0,72 \\
\hline Ascosmium dasycarpum & 0,0072 & 1 & 0,51 & 1,72 & 0,16 & 2,40 & 0,67 \\
\hline Myrtaceae & 0,0039 & 1 & 0,51 & 1,72 & 0,09 & 2,32 & 0,60 \\
\hline Casearia sylvestris & 0,0032 & 1 & 0,51 & 1,72 & 0,07 & 2,31 & 0,58 \\
\hline Psidium sp. & 0,0026 & 1 & 0,51 & 1,72 & 0,06 & 2,29 & 0,57 \\
\hline Plathymenia reticulata & 0,0023 & 1 & 0,51 & 0,00 & 0,05 & 0,56 & 0,56 \\
\hline Total & 4,4713 & 195 & 100 & 100 & 100 & 300 & 200 \\
\hline
\end{tabular}

Em que: $\mathrm{AB}=$ Área Basal; IND = Número de Indivíduos; $\mathrm{DR}=$ Densidade Relativa; $\mathrm{FR}=$ Freqüência Relativa; $\mathrm{DoR}=$ Dominância Relativa; $\mathrm{VI}=$ Valor de importância; $\mathrm{VC}=$ Valor de cobertura; N.I. = espécie não identificada.

Já no ambiente identificado como Areiãozinho foram amostrados 143 indivíduos, pertencentes a 15 famílias e 22 espécies (Tabela 3). As espécies com maior valor de importância foram Pouteria ramiflora $(43,56)$, Vochysia thyrsoidea $(34,13)$, Dalbergia miscolobium $(23,50)$ e Qualea grandiflora $(20,66)$. A área basal foi de 2,8953 $\mathrm{m}^{2}$.ha ${ }^{-1}$ e o valor de Shannon foi de 2,72.

São poucos os indivíduos de Vochysia thyrsoidea neste ambiente, entretanto seu VI suplanta a maioria das espécies, ao ponto de atingir a segunda colocação em termos de valor de importância. Certamente esta espécie passaria a ser a de maior VI na área, não fosse o grande número de Pouteria ramiflora presente no ambiente. Vale e Felfilli (2005), estudando a distribuição de biomassa seca de espécies arbóreas em áreas de Cerrado sensu strictu do Distrito Federal com a finalidade de selcionar indivíduos com grande potencial de incorporação de biomassa lenhosa para produção de lenha e carvão em regime de manejo florestal, identificaram que esta espécie acumulou, nas maiores classes de diâmetro encontradas, até $138,3 \mathrm{~kg}$ 
de Carbono/ha ${ }^{-1}$ indicando que é possível selecionar espécies que alcançam tamanho maior com uma grande capacidade de acumulação de carbono por planta. Esta informação é de grande utilidade para o manejo da produção de energia em área naturais de cerrado, pois possibilita a retirada de um número menor de indivíduos sem comprometer a produtividade da área de manejo florestal sustentável.

TABELA 3: Parâmetros estruturais e fitossociológicos no ambiente Areiãozinho (Neossolo Quartzarênico) na comunidade Água Boa 2, Rio Pardo de Minas (MG).

TABLE 3: Structural and phytosociology parameters in the Areiãozinho (Neossolo Quartzarênico) environment, Água Boa 2 community, Rio Pardo de Minas (MG).

\begin{tabular}{l|r|r|r|r|r|r|r}
\hline Nome Científico & $\begin{array}{c}\mathrm{AB} \\
\left(\mathrm{m}^{2} \mathrm{ha}^{-1}\right)\end{array}$ & $\mathrm{IND}$ & $\mathrm{DR}$ & $\mathrm{FR}$ & DoR & VI & VC \\
\hline Pouteria ramiflora & 0,5277 & 27 & 18,88 & 6,45 & 18,23 & 43,56 & 37,11 \\
Vochysia thyrsoidea & 0,7406 & 3 & 2,10 & 6,45 & 25,58 & 34,13 & 27,68 \\
Dalbergia miscolobium & 0,2505 & 12 & 8,39 & 6,45 & 8,65 & 23,50 & 17,04 \\
Qualea grandiflora & 0,2214 & 14 & 9,79 & 3,23 & 7,65 & 20,66 & 17,44 \\
Hymenaea stigonocarpa & 0,1003 & 11 & 7,69 & 6,45 & 3,46 & 17,61 & 11,16 \\
Byrsonima pachyphylla & 0,1120 & 9 & 6,29 & 6,45 & 3,87 & 16,61 & 10,16 \\
Kielmeyera coriacea & 0,0639 & 11 & 7,69 & 6,45 & 2,21 & 16,35 & 9,90 \\
Caryocar brasiliense & 0,3131 & 3 & 2,10 & 3,23 & 10,81 & 16,14 & 12,91 \\
Eugenia dysenterica & 0,0974 & 8 & 5,59 & 6,45 & 3,37 & 15,41 & 8,96 \\
Machaerium opacum & 0,0777 & 7 & 4,90 & 6,45 & 2,68 & 14,03 & 7,58 \\
Hancornia speciosa & 0,1002 & 8 & 5,59 & 3,23 & 3,46 & 12,28 & 9,05 \\
Erythroxylum sp.2 & 0,0427 & 6 & 4,20 & 6,45 & 1,47 & 12,12 & 5,67 \\
Annona crassiflora & 0,0825 & 4 & 2,80 & 6,45 & 2,85 & 12,10 & 5,65 \\
Aspidosperma tomentosum & 0,0348 & 5 & 3,50 & 6,45 & 1,20 & 11,15 & 4,70 \\
Byrsonima verbascifolia & 0,0505 & 6 & 4,20 & 3,23 & 1,74 & 9,16 & 5,94 \\
Schefflera macrocarpa & 0,0336 & 1 & 0,70 & 3,23 & 1,16 & 5,09 & 1,86 \\
Piptadenia viridiflora & 0,0029 & 1 & 0,70 & 3,23 & 0,10 & 4,02 & 0,80 \\
Psidium pohlianum & 0,0029 & 1 & 0,70 & 3,23 & 0,10 & 4,02 & 0,80 \\
Tabebuia sp. & 0,0029 & 1 & 0,70 & 3,23 & 0,10 & 4,02 & 0,80 \\
Diospyros burchellii & 0,0023 & 1 & 0,70 & 3,23 & 0,08 & 4,00 & 0,78 \\
N.I. & 0,0235 & 3 & 2,10 & 0,00 & 0,81 & 2,91 & 2,91 \\
Mortas & 0,0121 & 1 & 0,70 & 0,00 & 0,42 & 1,12 & 1,12 \\
\hline Total & 2,8953 & 143 & 100 & 100 & 100 & 300 & 200 \\
\hline En qua
\end{tabular}

Em que: $\mathrm{AB}=$ Área Basal; IND.= Número de Indivíduos; $\mathrm{DR}=$ Densidade Relativa; $\mathrm{FR}=$ Freqüência Relativa; DoR= Dominância Relativa; $\mathrm{VI}=$ Valor de importância; $\mathrm{VC}=$ Valor de cobertura; N.I.= espécie não identificada.

No ambiente identificado como Chapada de Latossolo amostraram-se um total de 63 indivíduos, pertencentes a 9 famílias e 17 espécies (Tabela 4). As espécies com maior valor de importância foram Dalbergia miscolobium (50,66), Hancornia speciosa (46,43), Pouteria ramiflora $(34,02)$, Aspidosperma tomentosum $(29,08)$ e Vochysia thyrsoidea $(22,92)$. A área basal foi de $0,8251 \mathrm{~m}^{2} \cdot \mathrm{ha}^{-1}$, obtendo-se o índice de Shannon de 2,48.

$\mathrm{Na}$ mesma pesquisa que identificou o potencial de incorporação de carbono em Vochysia thyrsoidea (VALE e FELFILLI, 2005) foi constatado que, dentre todas as espécies estudadas, a Dalbergia miscolobium apresentava maior potencial para uso em plantações de combustível vegetal em regime de manejo sustentável, pois seus indivíduos alcançavam as maiores dimensões e produtividade de madeira, além de apresentarem valores altos de poder calorífico, indicando boa aptidão para lenha e carvão-vegetal.

Hancornia speciosa, segunda espécie de maior VI no ambiente da Chapada de Latossolo, produz um fruto de grande relevância para as comunidades humanas e silvestres da região de Rio Pardo de Minas. É muito apreciado para o consumo in natura ou na fabricação de refrescos, sorvetes, doces secos, compotas, vinhos e vinagres (PARENTE et al., 1985, citado por MACHADO et al., 2004). A espécie também é de extrema relevância para a mastofauna, pois já foi constatada a procura por seus frutos por indivíduos de Lycalopes vetulus (raposa-do-campo) justamente nas estações de elevado déficit hídrico e grande escassez de alimentos (DALPONTE e LIMA, 1999). Existem, ainda, constatações sobre importância medicinal desta 
espécie que, dentre outras, segundo populações tradicionais da Bacia do Alto Paraguai e do Vale do Guaporé, no Estado do Mato Grosso, apresentam potencial hipoglicemiante, podendo ser utilizada no tratamento de diabetes (MACEDO e FERREIRA, 2004).

TABELA 4: Parâmetros estruturais e fitossociológicos no ambiente da Chapada (Latossolo) na comunidade Água Boa 2, Rio Pardo de Minas (MG).

TABLE 4: Structural and phytosociology parameters in the Chapada (Latossolo) environment, Água Boa 2 community, Rio Pardo de Minas (MG).

\begin{tabular}{l|c|c|c|c|c|c|c}
\hline Nome Científico & $\begin{array}{c}\mathrm{AB} \\
\left(\mathrm{m}^{2} \mathrm{ha}^{-1}\right)\end{array}$ & $\mathrm{IND}$ & $\mathrm{DR}$ & $\mathrm{FR}$ & $\mathrm{DoR}$ & $\mathrm{VI}$ & $\mathrm{VC}$ \\
\hline Dalbergia miscolobium & 0,2022 & 11 & 17,46 & 8,70 & 24,50 & 50,66 & 41,96 \\
Hancornia speciosa & 0,2065 & 8 & 12,70 & 8,70 & 25,03 & 46,43 & 37,73 \\
Pouteria ramiflora & 0,0911 & 9 & 14,29 & 8,70 & 11,04 & 34,02 & 25,32 \\
Aspidosperma tomentosum & 0,0503 & 9 & 14,29 & 8,70 & 6,10 & 29,08 & 20,39 \\
Vochysia thyrsoidea & 0,0912 & 2 & 3,17 & 8,70 & 11,05 & 22,92 & 14,23 \\
Enterolobium gummiferum & 0,0185 & 5 & 7,94 & 8,70 & 2,24 & 18,87 & 10,17 \\
Himatanthus obovatus & 0,0117 & 3 & 4,76 & 8,70 & 1,41 & 14,87 & 6,18 \\
Qualea parviflora & 0,0123 & 2 & 3,17 & 8,70 & 1,49 & 13,36 & 4,67 \\
Mortas & 0,0482 & 4 & 6,35 & 0,00 & 5,85 & 12,20 & 12,20 \\
Mimosa sp. & 0,0337 & 2 & 3,17 & 4,35 & 4,08 & 11,61 & 7,26 \\
Byrsonima pachyphylla & 0,0145 & 2 & 3,17 & 4,35 & 1,75 & 9,28 & 4,93 \\
Caryocar brasiliense & 0,0115 & 1 & 1,59 & 4,35 & 1,39 & 7,33 & 2,98 \\
Hymenaea stigonocarpa & 0,0115 & 1 & 1,59 & 4,35 & 1,39 & 7,33 & 2,98 \\
Stryphnodendron adstringens & 0,0081 & 1 & 1,59 & 4,35 & 0,99 & 6,92 & 2,57 \\
Kielmeyera coriacea & 0,0067 & 1 & 1,59 & 4,35 & 0,81 & 6,75 & 2,40 \\
Sclerolobium paniculatum var. subvelutinum & 0,0054 & 1 & 1,59 & 4,35 & 0,65 & 6,59 & 2,24 \\
N.I. & 0,0018 & 1 & 1,59 & 0,00 & 0,22 & 1,80 & 1,80 \\
\hline Total & 0,8251 & 63 & 100 & 100 & 100 & 300 & 200 \\
\hline En que AB Arat
\end{tabular}

Em que: $\mathrm{AB}=$ Área Basal; IND = Número de Indivíduos; $\mathrm{DR}=$ Densida de Relativa; $\mathrm{FR}=$ Freqüência Relativa; DoR = Dominância Relativa; VI = Valor de importância; VC = Valor de cobertura; N.I. = espécie não identificada.

No ambiente identificado como Tabuleiro amostraram-se 76 indivíduos, pertencentes a 10 famílias e 13 espécies (Tabela 5). As espécies com maior valor de importância foram Sclerolobium paniculatum var. subvelutinum (115,19), Lychnophora sp. (26,35), Miconia ferruginata $(21,50)$, Hancornia speciosa $(20,96)$ e Annona coriacea $(20,83)$. A área basal foi de $1,0123 \mathrm{~m}^{2}$.ha ${ }^{-1}$ e o índice de Shannon de 2,09.

S. paniculatum também foi indicada por Vale e Felfilli (2005) como espécie de grande potencial de uso em plantios para produção de energia, pelas mesmas razões destacadas para Dalbergia miscoluobium. Um destaque especial deve ser feito a esta espécie por apresentar grande dominância relativa (DoR) no ambiente de Tabuleiro (73,29\%, contra 8,01 da segunda espécie de maior DoR). Esta informação é de grande importância local, pois estes ambientes são os mais próximos das habitações da comunidade Água Boa 2, o que facilitaria sobremaneira a atividade de produção de energia florestal, atividade comum na povoação, em regime de manejo sustentável, guardando aos demais ambientes um uso conservacionista, focado na extração de frutos (Caryocar brasiliense e Hancornia speciosa, por exemplo). 
TABELA 5: Parâmetros estruturais e fitossociológicos no ambiente do Tabuleiro (Cambissolo Háplico) na comunidade Água Boa 2, Rio Pardo de Minas (MG).

TABLE 5: Structural and phytosociology parameters in the Tabuleiro (Cambissolo Háplico) environment, Água Boa 2 community, Rio Pardo de Minas (MG).

\begin{tabular}{l|c|r|r|r|r|r|r}
\hline Nome Científico & $\begin{array}{c}\mathrm{AB} \\
\left(\mathrm{m}^{2} \mathrm{ha}^{-1}\right)\end{array}$ & $\mathrm{IND}$ & $\mathrm{DR}$ & FR & DoR & VI & VC \\
\hline Sclerolobium paniculatum var. subvelutinum & 0,7419 & 26 & 34,21 & 7,69 & 73,29 & 115,19 & 107,5 \\
Lychnophora sp. & 0,0290 & 12 & 15,79 & 7,69 & 2,86 & 26,35 & 18,65 \\
Miconia ferruginata & 0,0465 & 7 & 9,21 & 7,69 & 4,60 & 21,50 & 13,81 \\
Hancornia speciosa & 0,0810 & 4 & 5,26 & 7,69 & 8,01 & 20,96 & 13,27 \\
Annona coriacea & 0,0265 & 8 & 10,53 & 7,69 & 2,62 & 20,83 & 13,14 \\
Kielmeyera speciosa & 0,0249 & 5 & 6,58 & 7,69 & 2,46 & 16,73 & 9,04 \\
Plathymenia reticulata & 0,0203 & 4 & 5,26 & 7,69 & 2,00 & 14,96 & 7,27 \\
Heteropterys byrsonimifolia & 0,0090 & 3 & 3,95 & 7,69 & 0,89 & 12,53 & 4,84 \\
Aspidosperma tomentosum & 0,0058 & 2 & 2,63 & 7,69 & 0,57 & 10,89 & 3,20 \\
Mortas & 0,0043 & 2 & 2,63 & 7,69 & 0,43 & 10,75 & 3,06 \\
Terminalia fagifolia & 0,0154 & 1 & 1,32 & 7,69 & 1,52 & 10,53 & 2,84 \\
Byrsonima verbascifolia & 0,0054 & 1 & 1,32 & 7,69 & 0,53 & 9,54 & 1,85 \\
Eremanthus glomeraptus & 0,0023 & 1 & 1,32 & 7,69 & 0,23 & 9,24 & 1,54 \\
\hline Total & 1,0123 & 76 & 100 & 100 & 100 & 300 & 200 \\
\hline
\end{tabular}

Em que: $\mathrm{AB}=$ Área Basal; $\mathrm{IND}=$ Número de Indivíduos; $\mathrm{DR}=$ Densidade Relativa; $\mathrm{FR}=$ Freqüência Relativa; DoR $=$ Dominância Relativa; $\mathrm{VI}=$ Valor de importância; $\mathrm{VC}=$ Valor de cobertura

A diversidade florística decresce em uma relação inversamente proporcional ao grau de antropização das áreas e distância dos locais de vivência (casas) da população local (Figura 1), sendo a área do Areião $(3,01)$, a que apresenta a maior diversidade seguida por Areiãozinho $(2,72)$, Chapada de Latossolo $(2,48) \mathrm{e}$ Tabuleiro (2,09). Amaral et al. (2006) encontrou H' = 3,087 em área similar em área de Cerrado rupestre em Brasília, sobre Latossolo Vermelho Amarelo. A comparação de valores indica que o ambiente do Areião possui alta diversidade e índices equivalentes aos encontrados em Cerrado stricto sensu, no Distrito Federal, Minas Gerais e Goiás (FELFILI et al., 1994; FELFILI e SILVA JUNIOR, 2001). Estes valores são considerados altos para as áreas de cerrado e são concordantes com os índices encontrados por Balduino et al. (2005). Porém, são considerados baixos se comparados com vegetação de áreas com formações da Mata Atlântica e da Floresta Amazônica, que têm índices de 3,72 a 4,3, respectivamente (SILVA e LEITÃO FILHO, 1982).

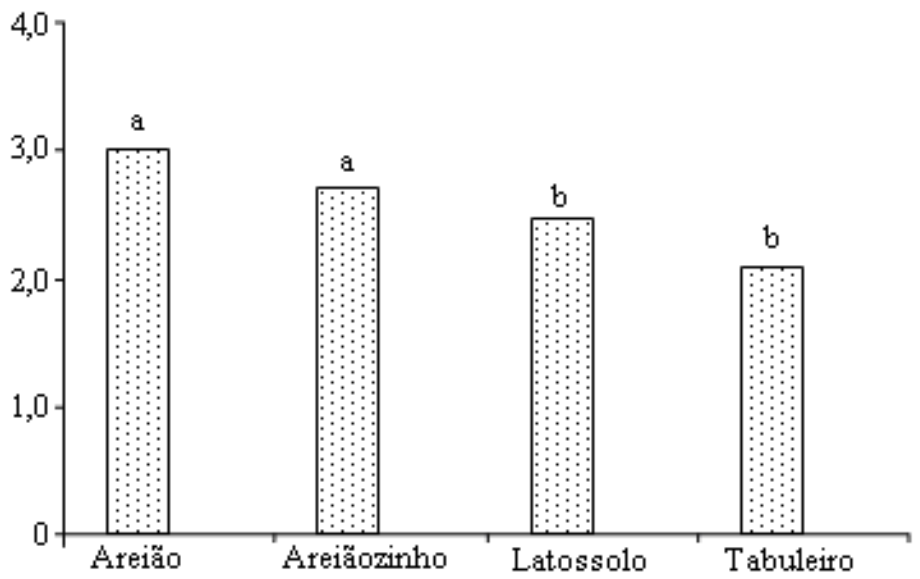

Letras minúsculas diferentes sobre as colunas indicam diferença significativa pelo teste de Tukey $(p<0,05)$

FIGURA 1: Comparação dos índices de diversidade de Shannon (H') por ambiente, em função do grau de antropização, na comunidade Água Boa 2, em Rio Pardo de Minas (MG).

FIGURE 1: Comparison of diversity index of Shannon (H') by environment, as a function of anthropization degree, in Água Boa 2 community, Rio Pardo de Minas (MG). 
A Tabela 6 apresenta os coeficientes de similaridade florística de Jaccard entre as áreas de estudo. Observa-se que para todas as combinações o valor do coeficiente foi inferior a 0,25 , indicando baixa similaridade entre as áreas, uma vez que duas áreas são consideradas florísticamente semelhantes quando este índice é superior a 0,25 (MULLER-DOMBOIS e ELLEMBERG, 1974, apud IVANAUSKAS, 1997). Vários fatores podem ser responsáveis pela baixa similaridade entre as áreas, entre eles as características de solo e o micro clima, que é diretamente influenciado pelo grau de preservação dos ambientes.

TABELA 6: Índices de similaridade de Jaccard entre os ambientes na comunidade Água Boa 2, Rio Pardo de Minas (MG).

TABLE 6: Jaccard index of similarity between the environments in the Água Boa 2 community, Rio Pardo de Minas (MG).

\begin{tabular}{l|c}
\hline Comparação entre ambientes & Índice de Similaridade de Jaccard \\
\hline Areião - Areiãozinho & 0,20 \\
Areião - Chapada de Latossolo & 0,23 \\
Areião - Tabuleiro & 0,12 \\
Areiãozinho - Chapada de Latossolo & 0,18 \\
Areiãozinho - Tabuleiro & 0,08 \\
Chapada de Latossolo - Tabuleiro & 0,11 \\
\hline
\end{tabular}

Os ambientes com os maiores índices de diversidade (Areião e Areiãozinho) ocorreram em solo de menor fertilidade natural e com textura mais arenosa, o Neossolo Quartzarênico. Nesse solo, sua menor aptidão agrícola diminuiu a demanda de uso para a agricultura e plantios florestais homogêneos. Ao passo que os ambientes com maior capacidade de suporte, textura mais argilosa e melhor capacidade de retenção de bases tiveram menores índices de diversidade, indicando que a variação da diversidade florística foi influenciada pelo uso e manejo dos ambientes.

\section{CONCLUSÕES}

Com a proximidade das áreas onde se estabelecem as populações humanas da comunidade Água Boa 2 há indicações científicas da redução da diversidade arbórea das áreas de gerais (chapadas de uso comum), determinadas pelo índice de Shannon. O Areião e o Areiãozinho apresentaram maior diversidade que os ambientes Chapada de Latossolo e Tabuleiro, possivelmente, por influência da grande pressão de uso dos dois últimos.

A ocorrência natural de espécies de maior potencial para uso em plantios florestais de produção de energia (lenha e carvão) nos ambientes mais próximos às habitações da comunidade (Vochysia thyrsoidea, Dalbergia miscolobium) e, por sua vez, nos ambientes mais distantes e de difícil acesso, espécies de grande aptidão para produção de frutos (Caryocar brasiliense, Hancornia speciosa) indicam que o ordenamento das atividades agro-extrativistas da comunidade Água Boa 2 pode vir a equacionar problemas de desequilíbrio entre o desenvolvimento da economia local e a sustentabilidade dos ambientes naturais.

O índice de similaridade de Jaccard mostrou pouca aproximação florística entre os ambientes.

\section{AGRADECIMENTOS}

Ao Sindicato dos Trabalhadores Rurais de Rio Pardo de Minas, ao Centro de Agricultura Alternativa do Norte de Minas Gerais (CAA), aos moradores da comunidade Água Boa e ao pesquisador da Embrapa Cerrado Dr. João Roberto Correia pelo apoio ao trabalho. Agradecimento especial a Dra. Rafaela Campostrini Forzza da Fundação Jardim Botânico do RJ.

\section{REFERÊNCIAS BIBLIOGRÁFICAS}

ALHO, C.J.R.; MARTINS, E.S. De grão em grão, o Cerrado perde espaço. (Cerrado - Impactos do Processo de Ocupação). Brasília, DF: WWF \& PRÓ-CER. 1995. 66p.

AMARAL, A.G.; PEREIRA, F.F.O.; MUNHOZ, C.B.R. Fitossociologia de uma área de Cerrado rupestre na Fazenda Sucupira, Brasília-DF. Cerne, Lavras, v.12, n.4, p.350-359, out./dez. 2006.

ASSUNCAO, S.L.; FELFILI, J.M. Fitossociologia de um fragmento de cerrado sensu strictu na APA do Paranoá, DF, Brazil. Acta Botânica Brasílica, São Paulo, v.18, n.4, p.903-909, out./dez. 2004.

BALDUINO, A.P.C. et al. Fitossociologia e análise comparativa da composição florística do cerrado da flora de Paraopeba-MG. Revista Árvore, Viçosa, v.29, n.1, p.25-39, jan./fev. 2005. 
DALPONTE, J. C.; LIMA, E. de S. Disponibilidade de frutos e a dieta de Lycalopex vetulus (Carnivora - Canidae) em um cerrado de Mato Grosso, Brasil. Revista Brasileira de Botânica, São Paulo, v. 22, suppl.2, out. 2009.

DAYRELL, C.A. Os geraizeiros descem a serra ou a agricultura de quem não aparece nos relatórios dos agrobusiness. In: GUIMARÃES, P.W. et al. (Eds.). Cerrado e desenvolvimento: tradição e atualidade. Montes Claros, Unimontes, 2000. p.191-274.

FELFILI, J.M.; SILVA JÚNIOR, M.C. (orgs.). Biogeografia do Bioma Cerrado: estudo fitofisionômico na chapada do Espigão mestre do São Francisco. Brasília: Universidade de Brasília, Faculdade de Tecnologia, Departamento de Engenharia Florestal, 2001. 152p.

FELFILI, J.M. et al. Projeto biogeografia do bioma cerrado: vegetação e Solos. Cadernos de Geociências do IBGE, Rio de Janeiro, v.12, p.75-166, 1994.

FERREIRA, R.O. Análise dos programas do Setor Florestal Brasileiro, implantados no período de 1966-1987. 2005. 76 f. Monografia (TCC de graduação em Engenharia Florestal) - Universidade Federal Rural do Rio de Janeiro, Seropédica.

FONSECA, M.S. da; SILVA JÚNIOR, M.C. Fitossociologia e similaridade florística entre trechos de Cerrado sentido restrito em interflúvio e em vale no Jardim Botânico de Brasília, DF. Acta Botânica Brasilica, v.18, n.1, p.19-29, jan./mar. 2004.

IBGE - Instituto Brasileiro de Geografia e Estatística. 2006. http://www.ibge.gov.br/ acessado em 10 de julho de 2007.

IVANAUSKAS, N.M. Caracterização florística e fisionômica da floresta atlântica sobre a formação PariqueraAçu, na zona da morraria costeira do estado de São Paulo. 1997. Dissertação (Mestrado) - Universidade Estadual de Campinas, Campinas.

MACEDO, M. e FERREIRA, A. R.. Plantas hipoglicemiantes utilizadas por comunidades tradicionais na Bacia do Alto Paraguai e Vale do Guaporé, Mato Grosso - Brasil. Revista Brasileira de Farmacologia, v.14, suppl.01, p. 45-47. 2004.

MACHADO, L. de L. et al. Seleção de matrizes e clones de mangabeira para o cultivo in vitro. Pesquisa Agropecuária Brasileira, Brasília, v.39, n.5, p. 431-435, mai. 2004.

MEIRA NETO, J.A.A.; SAPORETTI-JÚNIOR, A.W. Composição florística em cerrado no Parque Nacional da Serra do Cipó, MG. Revista Árvore, Viçosa, v.26, n.5, p. 645-648, set./out. 2002.

OLIVEIRA, M.C. et al. Avaliação de diferentes níveis de intervenção na florística, diversidade e similaridade de uma área de Cerrado stricto senso. Cerne, Lavras, v.12, n.4, p. 342-349, out./dez. 2006.

PIMM, S.L. The complexity and stability of ecosystems. Nature, v.307, p.312-26, jan. 1984.

PIVELlO, V.R. e COUTINHO, L.M. A qualitative sucessional model to assist in the management of Brazilian cerrados. Forest Ecology and Management, v.87, p. 127-138, mar. 1996.

RIBEIRO, J.F.; WALTER, B.M.T. (Eds.). Fitofisionomias do Cerrado. In: SANO, S.M.; ALMEIDA, S.P. (Eds.) Cerrado: ambiente e flora, Planaltina, Embrapa CPAC, 1998. p.89-166.

SILVA, A.F.; LEITÃO FILHO, H.F. Composição florística e estrutura de um trecho de mata atlântica de encosta no município de Ubatuba (São Paulo, Brasil). Revista Brasileira de Botânica, São Paulo, v.5, p.43-52, jan./fev. 1982.

SILVA JUNIOR, M.C. da. 100 árvores do Cerrado - Guia de campo. Brasília: Rede de Sementes do Cerrado, 2005. $278 p$.

SYLVESTRE, L.S.; ROSA, M.M.T. Manual metodológico para estudos botânicos na Mata Atlântica. SeropédicaRJ: EDUR, 2002. 122p.

VALE, A. T. do e FELFILI, J. M. Dry biomass distribution in a cerrado sensu stricto site in Brazil central. Revista Árvore, Viçosa, v.29, n.5, p. 661-669, set./out. 2005. 